\title{
Clinical Profile of Patients with Manus Fracture Caused by Firecracker Blast
}

\author{
Pamudji Utomo',2,3), Totok Siswanto4) \\ 1)Department of Orthopaedics and Traumatology, Prof. Dr. R. Soeharso Orthopaedics Hospital \\ 2)Faculty of Medicine, Universitas Sebelas Maret \\ 3)Karima Utama Surgical Hospital, Surakarta \\ 4)Department of Emergency, Karima Utama Surgical Hospital, Surakarta
}

\section{ABSTRACT}

Background: Fireworks are traditionally used by various cultures or groups for celebrations. Estimated 10,000 to 12,600 people are injured because of fireworks in America every year. The type of fireworks that cause the highest injury is firecrackers with the incidence rate of $30 \%$ to $67 \%$ of all cases of injury due to fireworks. Indonesia is a country with the largest Muslim population in the world and firecrackers are often used to welcome Ramadan and Eid al-Fitr. This study aimed to report the Clinical profile of patients with manus fracture caused by firecracker blast. Case Presentation: The case study was taken from patients of Karima Utama Surgical Hospital, Surakarta, Indonesia, during Ramadan and Eid al-Fitr (from May 14 to June 15) 2018. A total of 36 patients were fractured due to firework explosions recorded in medical records during that period. Data such as gender, age and fracture diagnosis were collected in this study.

Results: Males have a higher prevalence of 28 (78\%) than female 8 (22\%), with the highest group age between 11 to 20 years with 11 cases (31\%) and more than 60 years being the lowest age group with 2 (6\%) cases of a total of 36 respondents. The right hand as the dominant hand has an injury incidence rate of 31 (86\%) compared to the left hand 5 (14\%) and more often occurs single fracture 22 (61\%) compared to multiple fractures 14 (39\%) including the amputated phalanx.

Conclusion: Our study showed 36 patients had fractures of the manus due to firecrackers, with the majority of male victims 28 (78\%) and single manus fractures 22 (61\%) with the right-hand dominance at the age between 11 to 20 years.

Keywords: manus fracture, firecracker

\section{Correspondence:}

Pamudji Utomo. Department of Orthopedics and Traumatology Prof. Dr. R. Soeharso Orthopedics Hospital, Surakarta. Email: utomodr@yahoo.com.

\section{Cite this as:}

Utomo P, Siswanto T (2020). Clinical Profile of Patients with Manus Fracture Caused by Firecracker Blast. Indones J Med. 05(01): 57-62. https://doi.org/10.26911/theijmed.2020.05.01.09

c) (1) Indonesian Journal of Medicine is licensed under a Creative Commons

EY NC SA Attribution-NonCommercial-ShareAlike 4.o International License.

\section{BACKGROUND}

Firecrackers are traditionally used by various cultures or groups for celebrations. Many publications that report firecrackers abuse are a major cause of injuries from various types of celebrations throughout the world. Firecrackers are used in various kinds of celebrations in the world such as Independence Day and Halloween in America, Ashura in Morocco, Hari Raya in Malaysia and Eid alFitr in Indonesia (Adhikari et al, 2013; Cletus et al., 2016; Gelbart et al., 2007; Gordon et al., 2015; Hatamabadi et al., 2013).

Most victims of firecrackers blast have injuries to the face, arms and hands. The incidence rate in America is 1,130 upper limb injuries from 100,000 patients per year. The most frequent part of the injury is the finger (38.4\%), and the most common injury is a fracture (29.2\%) (Feehan and Sheps, 2006; Jameel et al, 2018; Lemonic, 2011; Ootes et al., 2017). 
Indonesia is a country with the largest Muslim population in the world, which is recorded in 2010 with 205,126,295 Muslim residents or $88.22 \%$ of the total population in 2010 and predicted in 2020 become 232,342,367 Muslim residents or around 88.22\% of the total population in 2020. Every year all Muslims in the world celebrate Eid after one month of fasting during Ramadhan so do in Indonesia. Firecrackers are still often used to celebrate Eid al-Fitr or Ramadhan in Indonesia (Feehan and Sheps, 2006; Kettani, 2010; Ootes et al., 2017; Premlal et al., 2018).

The purpose of this study was to define the clinical profile of manus fractures caused by explosions of firecrackers in the last year Ramadan and Eid (May 14 - June 15) 2018 at the Karima Utama Surgical Hospital. Knowing the quantity and pattern of fracture events can be a reference for the government to make policies and hospitals in preparation.

\section{CASE PRESENTATION}

The case study was taken from patients of Karima Utama Surgical Hospital, Surakarta, Indonesia, during Ramadan and Eid al-Fitr (from May 14 to June 15) 2018. A total of 36 patients were fractured due to firework explosions recorded in medical records during that period. Data such as gender, age and fracture diagnosis were collected in this study.

\section{RESULTS}

Within study period the diagnosed manus fracture caused by explosions of firecrackers which recorded in the medical records at Karima Utama Surgical Hospital during 2018 there were 36 patients regardless of gender and age. There is a greater prevalence of men than women 3.5: 1.

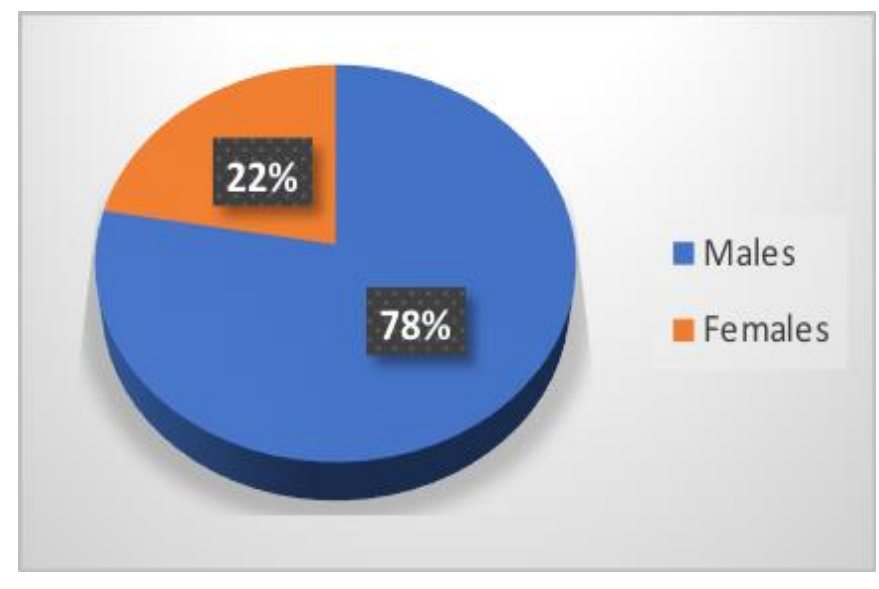

\section{Figure 1. Gender Distribution of Samples $(n=36)$}

Figure 1 shows the gender distribution. Among 36 patients, there were 28 (78\%) men and 8 (22\%) women. Figure 2 shows the right manus fractures more often 31 (86\%) than the left manus 5 (14\%). Figure 3 shows that single fracture occurs more often 22 (61\%) than multiple fractures 14 (39\%). Multiple fractures that occur include the amputated phalanx.

Table 1 showed age distribution of samples. Table 1 showed that the highest incidence occurs at the age of 11 to 20 years (31\%) and the lowest at the age of more than 60 years (6\%). 
Utomo et al./ Clinical profile of manus fracture caused by firecracker blast

Table 1. Age Distribution of Samples $(n=36)$

\begin{tabular}{ccc}
\hline Age (years) & n & \% \\
\hline O-10 & 3 & $8 \%$ \\
$11-20$ & 11 & $31 \%$ \\
$21-30$ & 9 & $25 \%$ \\
$31-40$ & 6 & $17 \%$ \\
$41-50$ & 2 & $6 \%$ \\
$51-60$ & 3 & $8 \%$ \\
$\geq 60$ & 2 & $6 \%$ \\
Total & 36 & $100 \%$ \\
\hline
\end{tabular}

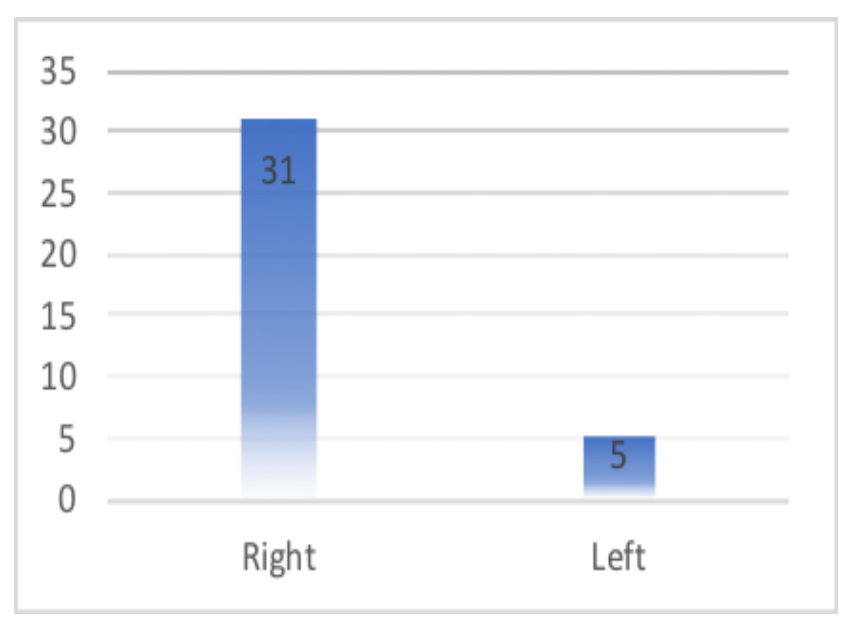

Figure 2. Fractured Manus Distribution of Samples $(n=36)$

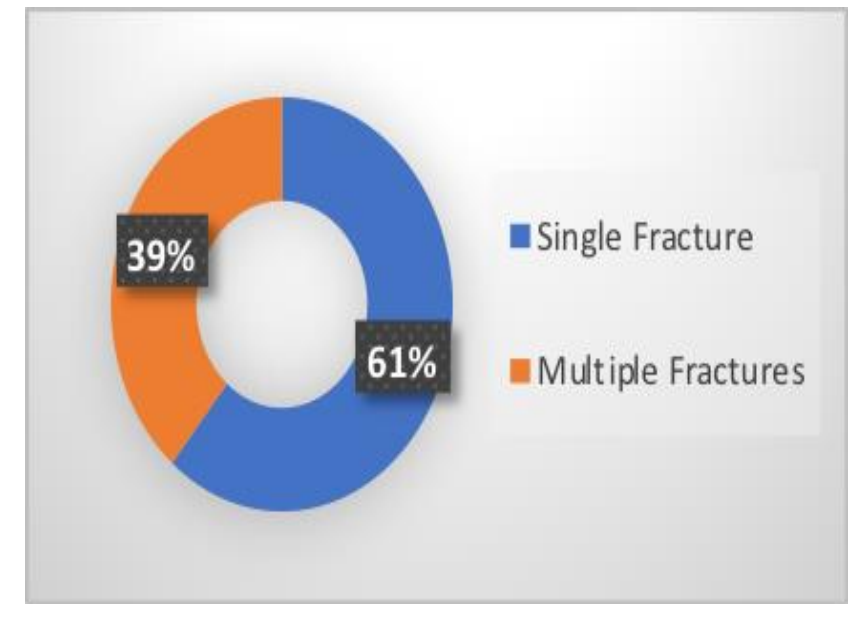

Figure 3. Distribution of Manus Fracture Types $(n=36)$
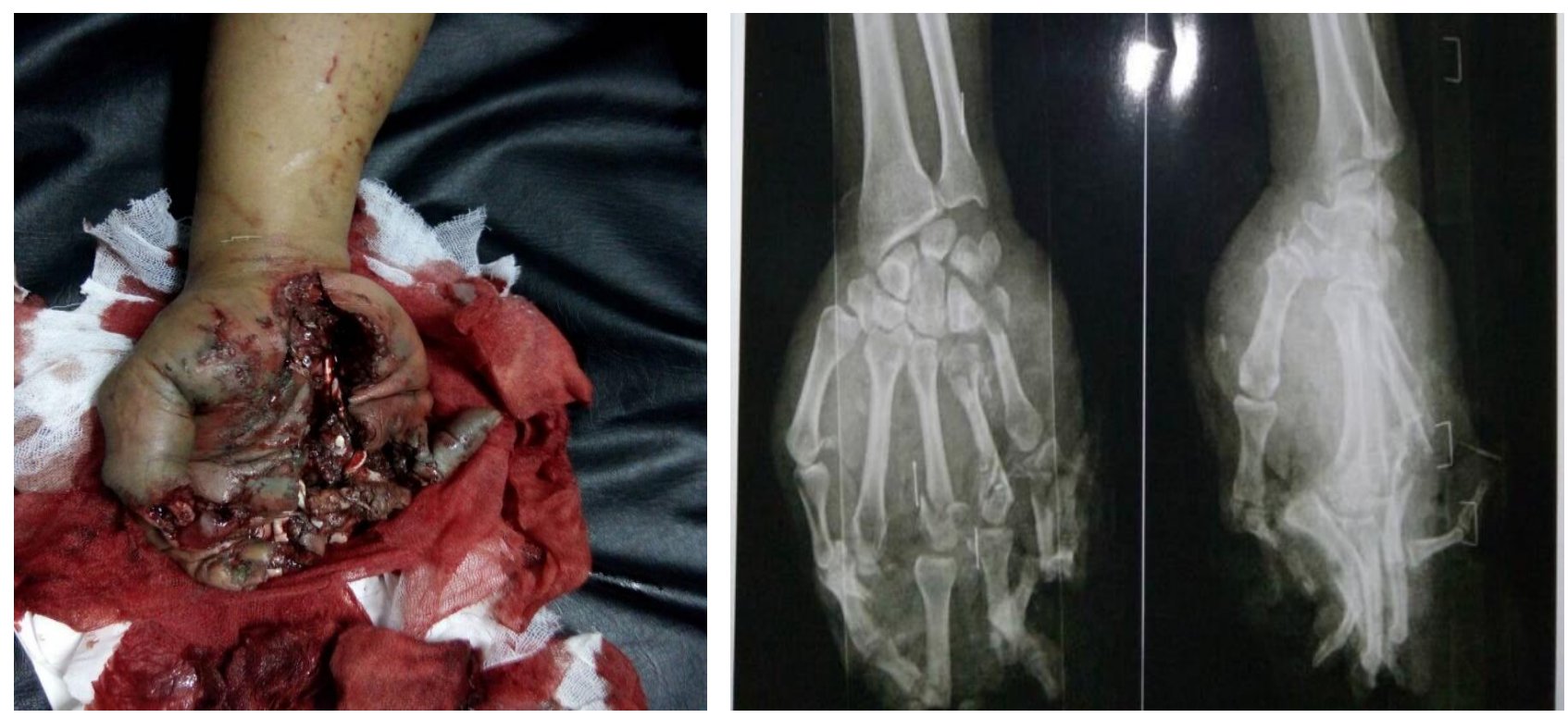

Figure 4. Wounds and X-Ray of Multiple Fractures Manus Caused by Firecracker Blast 


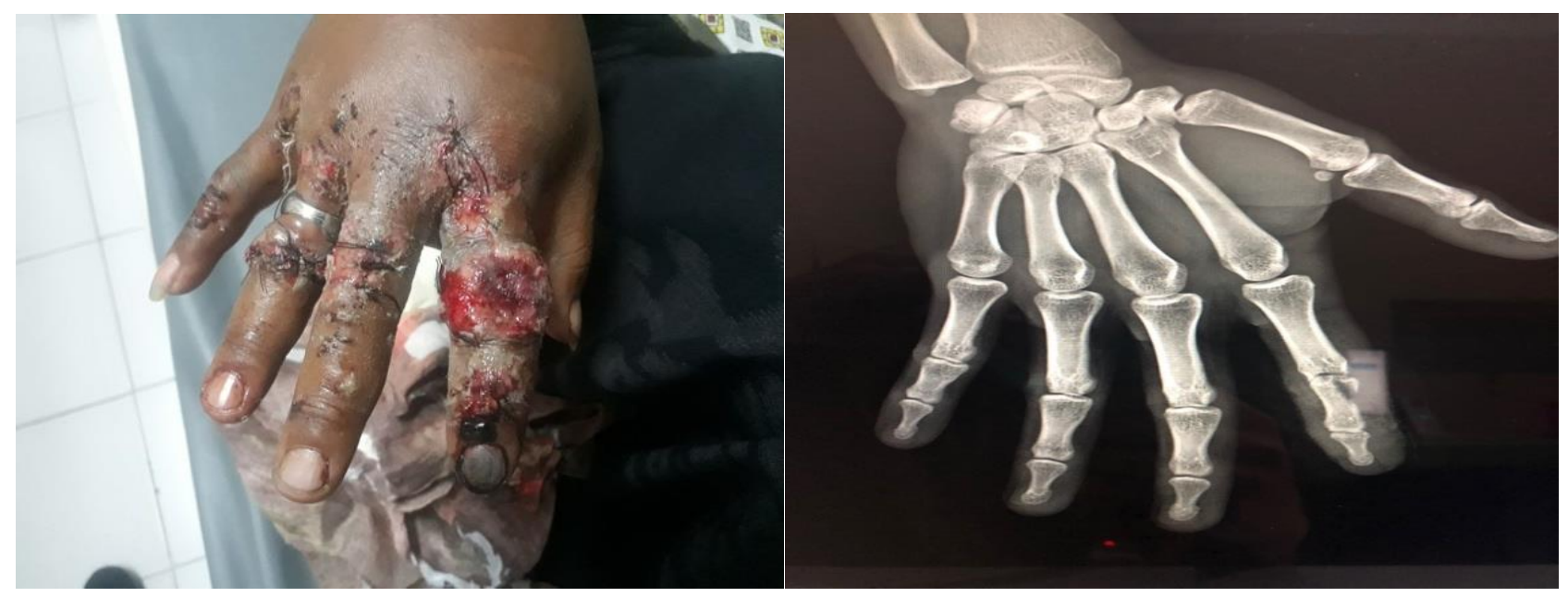

Figure 4. Wounds and X-Ray of Multiple Fractures Manus Caused by Firecracker Blast

\section{DISCUSSION}

Fireworks often used at commemorative events because the sound, light and color produced when they erupt represent happiness and excitement. Estimated 10.000 to 12.600 people are injured because of fireworks in America every year. The type of fireworks that cause the highest injury is firecrackers with the incidence rate of $30 \%$ to $67 \%$ of all cases of injury due to fireworks (Gelbart et al., 2007; Gopalakrishnan et al., 2016; Hazani et al., 2009; Une et al., 2015). The hand is the body part that most often injured by fireworks with the incidence rate around $20 \%$ to $56 \%$ of all cases. The right hand which is more dominant in the general population has a higher incidence rate of 61.50\% in all cases (Gelbart et al., 2007; Hatamabadi et al., 2013; Pilling and Govander, 2016).

In the study above, it was found that men had a higher incidence rate of 28 (78\%) than female 8 (22\%). Higher incidence rates in male were also found in the study conducted by Gopalakrishnan et al. (2016) with $78 \%$ male patients, Rajeswari et al. (2016) with $66 \%$ male patients, Hatamabadi et al. (2013) with $87 \%$ patients, Pilling and
Govender (2016) 70.8\% from all patients were male.

The average age of this study was $\mathbf{2 7 . 5}$ years with the highest incidence rate at the age between 11 to 20 years old with 11 (31\%) respondents and the lowest incidence rate at the age of more than 60 years 2 (6\%) respondents. This result is the same as the study conducted by Rajeswari et al., (2016) 46\% of respondents aged between 13 to 20 years old have the highest incidence.

Single fractured manus more often occur in the man caused by firecrackers in this study counted 22 (61\%) compared to multiple fractures 14 (39\%). Multiple fractures including amputated phalanx. Research conducted by Ootes et al. (2012) states that of all firecrackers injuries $38.4 \%$ of them were injuries to the fingers.

Firecrackers are the type of fireworks that most often causes injury and hands are the parts of the body that are most often injured. In this study, it was found that men had a higher incidence of $28(78 \%)$ than female 8 (22\%). The dominant right hand has a higher incidence rate. The age group with the highest manus fractures is between 11 to 20 years $11(31 \%)$ respondents and the age group with the lowest incidence is more than 
Utomo et al./ Clinical profile of manus fracture caused by firecracker blast

60 years 2 (6\%). The hand fractures caused by firecrackers in our study, there were 22 (61\%) patients experiencing a single fracture, 14 (39\%) had multiple fractures.

\section{AUTHOR CONTRIBUTION}

Pamudji Utomo and Totok Siswanto conceived of the presented idea, contributed to the design and implementation of the study. All authors discussed the results and contributed to the final manuscript.

\section{CONFLICT OF INTEREST}

The authors declare no conflict of interest in this study.

\section{FUNDING AND SPONSORSHIP}

This study used the authors' independent fund.

\section{ACKNOWLEDGEMENT}

We would like to show our gratitude to the Karima Utama Special Orthopedic Hospital that support and give permission for this study.

\section{REFERENCE}

Adhikari S, Bandyopadhyay T, Sarkar T, Saha JK (2013). Blast injuries to the hand: Pathomechanics, patterns and treatment. J Emerg Trauma Shock. 6(1): 29-36. https://dx.doi.org/10.4103\%2Fo974-2700.106322

Cletus O, Kennedy E, Gabriel O, Benjamin O, Christopher O, Joyce I (2016). Blast injuries to the hand from celebrations gone wrong - A series of disabling injuries from firecrackers. Int $\mathrm{J}$ of Forensic Med Invest. 2(1): 36-40. https://doi.org/10.21816/ijfmi.v2i1.19

Feehan LM, Sheps SB (2006). Incidence and demographics of hand fractures in British Columbia, Canada: a population-based study. J Hand Surg Am. 31(7): 1068-74. https://doi.org/10.1016/j.jhsa.2006.06.006
Gelbart BR, Ukunda UNF, Muller J, Stuart W (2008). An evaluation of firework injuries to the hand - New York 2007. SA Orthopaedic Journal. 16-26

Gopalakrishnan R, Shivakami T, Sugapradha GR (2016). Prevalence and pattern of cracker blast injury of the hand. Int Surgery Journal. 3(2): 831-836. http://dx.doi.org/10.18203/2349-2902.isj20161157

Gordon W, Kuhn K, Staeheli G, Dromsky D (2015). Challenges in definitive fracture management of blast injuries. Curr Rev Musculoskelet Med. 8: 290-297. https://dx.doi.org/10.1007\%2Fs12178-0159286-7.

Hatamabadi HR, Tabatabaey A, Khoramian KM (2013). Firecracker injuries during chaharshanbeh soori festival in Iran: A Case Series Study. Arch Trauma Res. 2(1): 46-49. https://dx.doi.org/10.5812\%2Fatr.9250

Hazani R, Buntic RF, Brooks D (2009). Patterns in blast injuries to the hand. HAND (N.Y). 4(1): 44-49. https://doi.org/10.1007/s11552-008-9125-Z

Jameel MR, Galketiya KB, Samarasinghe TM (2018). Penetrating injury to Zone II of the neck causing laryngotracheal injury following a firecracker blast: first reported case. The Sri Lanka Journal of Surgery. 36(4): 35-37. http://doi.org/$10.4038 /$ sljs.v36i4.8558

Kettani H (2010). Muslim population in Asia: 1950 - 2020. Int J of Environ Sci Dev. 1(2): 143-153. http://www.ijesd.org/papers/28-D437.pdf

Lemonic DM (2011). Bombings and blast injuries: A primer for physicians. American J Clin Med. 8(3): 134-140. https://www.aapsus.org/wp-content/uploads/ajcmfour.pdf

Ootes D, Lambers KT, Ring DC (2017). The epidemiology of upper extremity injuries presenting to the emergency de- 
Utomo et al./ Clinical profile of manus fracture caused by firecracker blast

partment in the United States. HAND

(N.Y). 7(1):18-22. Retrieved from https://www.nytimes.com/interactive/2018 /05/20/nyregion/affordable-housingnyc.html

Pilling T and Govander T (2016). Profile and Management of the Firework-Injured Hand. South African Family Practice. 58(2): 48-53. https://doi.org/10.1080/20786190.2015.1125167

Premlal AP, Mohan M, Beevi K, Komalarani $\mathrm{T}$ (2018). Clinical profile of firework disaster in Kerala: Lesson learnt. Int Sur J. 5(8): 2771-2776
Rajeswari B, Shankari B, Selvaraj A (2016). Epidemiology of cracker (firework) injuries in a tertiary burn care center. Int J Applied Sci. 4(1): 6-18. http://dx.doi.org/10.18203/2349-2902.isj20182995.

Une V, Khaire BS, Melmane S (2015). A Rare Injury Associated with Firecracker. Bombay Hospital J. 57(2): 194-196. Retrieved from https://pdfs.semanticscholar.org/af35/ec3b2f242f688fdo371 99e7c6ec7da8ed2af.pdf 